\title{
Attitudes of teenagers in Liverpool to breast feeding
}

\author{
Jacqueline E M Gregg
}

\begin{abstract}
To explore the attitudes of teenagers to breast feeding in Liverpool, where only $30-35 \%$ of babies are breast fed, a questionnaire survey of $\mathbf{4 0 0}$ pupils aged 14 and 15 was carried out. Only $70(18 \%)$ had been breast fed. Three quarters of the pupils thought breast feeding was healthier than bottle feeding and that it was natural, but $32(8 \%)$ thought that it was rude. Most pupils said that breast feeding should be discussed in class.

More open discussion might reduce embarrassment and also help prepare for parenthood.
\end{abstract}

\section{Introduction}

The incidence of breast feeding in England and Wales increased from $51 \%$ in 1975 to $67 \%$ in 1980 , bu since then has remained unchanged. 'In Liverpool it is only $30-35 \%$. We carried out a questionnaire survey of teenagers in Liverpool to ascertain their attitudes to infant feeding; discussion of infant feeding practices with schoolchildren may help improve breast feeding statistics. $^{2}$

Subjects, method, and results

A questionnaire survey of 400 fourth form pupils from 10 comprehensive schools was carried out. The questionnaire was anonymous and comprised 22 multiple choice questions with space for comment. All 220 girls (103 aged 14 and 117 aged 15) and 177 of the 180 boys ( 127 aged 14 and 50 aged 15 ) were included in the study. The $\chi^{2}$ test was used for statistical evaluation.

Only $70(18 \%)$ pupils had been breast fed; $143(36 \%)$ did not know how they had been fed. Eighty eight $(40 \%)$ girls and $49(28 \%)$ boys $(\mathrm{p}<0.02)$ had seen a relative breast feeding. In contrast; $209(95 \%)$ girls and $148(84 \%)$ boys $(\mathrm{p}<0.001)$ had seen a relative bottle feeding.

The pupils considered breast feeding to be healthier than bottle feeding $(298,75 \%)$ and natural $(305,77 \%)$, but thought that infants should be breast fed only for six months; they thought that bottle feeding was convenient $(239,60 \%)$ and modern $(142,36 \%)$. Only $14(4 \%)$ thought that breast feeding was modern, and $43(11 \%)$ thought that it was convenient. More girls than boys $(55(25 \%) v 25(14 \%) ; \mathrm{p}<0.01)$ thought that returning to work would prevent women breast feeding.

Fifty eight (15\%) pupils agreed that breast feeding makes people think of "page three girls," making them embarrassed and less likely to breast feed. Forty two $(11 \%)$ thought breasts were rude, and $32(8 \%)$ thought that breast feeding was rude. Half the pupils felt that choice of feeding method should be a joint decision for parents.

A higher proportion of boys than girls (105/166 $(63 \%) v 112 / 218(51 \%) ; \mathrm{p}<0.05)$ would choose breast feeding for a child of their own. Two definitions emerged, however: those who would solely breast feed
(50 boys ( $30 \%), 46$ girls (21\%)) and those who would breast feed in acceptable places and bottle feed elsewhere ( 55 boys ( $33 \%), 66$ girls (30\%)). Of 104 girls who chose the second definition or to bottle feed, 43 stated that embarrassment would prevent them breast feeding and 32 considered bottle feeding to be more convenient as they would not wish to breast feed outside the home.

The pupils were asked where they thought it was acceptable for another person's baby and for their own future infants to be breast fed. Most thought that breast feeding should be done in private (table). One

Pupils' opinions on where their own and other infants could be breast fed. Numbers in parentheses are percentages

\begin{tabular}{lccccc}
\hline & \multicolumn{2}{c}{ Other infants } & & \multicolumn{2}{c}{ Own infants } \\
\cline { 2 - 3 } \cline { 6 - 6 } & $\begin{array}{c}\text { Boys } \\
(\mathbf{n}=175)^{\star}\end{array}$ & $\begin{array}{c}\text { Girls } \\
(\mathbf{n}=220)\end{array}$ & $\begin{array}{c}\text { Boys } \\
(\mathbf{n}=175)^{\star}\end{array}$ & $\begin{array}{c}\text { Girls } \\
(\mathbf{n}=220)\end{array}$ \\
\hline At home alone & $173(99)$ & $220(100)$ & & $175(100)$ & $220(100)$ \\
Baby's father present & $157(89)$ & $189(86)$ & & $153(87)$ & $179(81)$ \\
Female family present & $111(63)$ & $136(62)$ & & $94(53)$ & $104(47) \ddagger$ \\
Male family present & $55(31)$ & $30(14) \dagger$ & & $49(28)$ & $17(8) \dagger \ddagger$ \\
Female friend present & $99(56)$ & $115(52)$ & & $78(44)$ & $86(39) \ddagger$ \\
Male friend present & $22(12)$ & $9(4) \dagger$ & & $21(12)$ & $4(2) \dagger$ \\
Other children present & $29(16)$ & $49(22)$ & & $22(12)$ & $25(11) \ddagger$ \\
On bus & $4(2)$ & $3(1)$ & & $2(1)$ & \\
In park & $7(4)$ & $8(4)$ & & $4(2)$ & $3(1)$ \\
At shops & $4(2)$ & $4(2)$ & & $1(<1)$ & \\
In restaurant & $6(3)$ & $5(2)$ & & $5(3)$ & $1(<1)$ \\
\cline { 1 - 1 } & & & & &
\end{tabular}

$\star 2$ boys did not answer the question.

$t p<0.01$ for responses of girls compared with boys.

$\ddagger \mathrm{p}<0.01$ for responses of girls comparing their own and other infants.

boy expressed surprise that anyone would breast feed in front of children, as his father had repeatedly told him not to look at the women pictured on page three. Another stated that breast feeding should not be allowed in restaurants as "it would put you off your food."

Most pupils (385, 97\%) said breast feeding should be discussed with both sexes in class and thought better education would ecourage women to breast feed. Only 30 boys (17\%) and $74(34 \%)$ girls had heard the subject discussed in school. Pupils who had been breast fed themselves were significantly more likely to choose breast feeding for a future child than those who had been bottle fed $(61 / 67 v 63 / 172 ; \mathrm{p}<0 \cdot 001)$. Similarly, pupils who had seen a baby breast fed were more likely to choose breast feeding than those who hadn't $(96 / 132$ $v$ 122/246; $\mathrm{p}<0.001$ ).

\section{Discussion}

In an area where the prevalence of breast feeding is so low, the pupils' responses were surprisingly positive. Embarrassment was the main reason for not wanting to breast feed, and this may decrease as the teenagers come to terms with their developing sexuality. Canadian pupils in a similar study were less inhibited than the Liverpool pupils, but more had been breast fed. ${ }^{3}$ Liverpool's low incidence of breast feeding suggests that attitudes held as children extend into the childbearing years, which may not be far ahead as $15 \%$ 
of the 3154 deliveries in one Liverpool hospital in 1986 were to teenage girls. Only $14 \%$ breast fed their infants.

Many pupils regarded bottle feeding as more convenient and fashionable. Cost was unimportant. Some girls thought that formular feeds were free as milk tokens were available for all. One boy argued that bottle feeding was safer, as the baby could not catch AIDS.

The most positive influence on the pupils' choice of feeding was previous experience of breast feeding; this has been shown in other studies. ${ }^{+5}$ What are the implications for change where few have the opportunity to see a baby breast fed? Infant feeding should be a topic in health education for both sexes from the earliest school years. This study suggests that by the fourth form embarrassment is firmly fixed. More open discussion on breast feeding and its merits might reduce embarrassment and modify society's acceptance of the breast as a purely sexual organ. Most of our schoolchildren will become parents. School should be preparing them for parenthood as well as a career.

I thank Dr M Pearson, lecturer in medical sociology, university department of general practice, for advice in preparing the questionnaire and Dr E Poskitt for constructive criticism. Special thanks go to the staff and pupils who took part.

1 Martin J, White A. Infant fieding 1985. London: Office of Population Censuses and Surveys, 1988.

Eastham E, Smith D, Poole D, Neligan G. Further decline of breast feeding. $\mathrm{Br}$ Med f 1976;i:305-7.

3 Ellis DJ. Secondary school students' attitudes and beliefs about breast feeding. f Sch Health 1983;53:600-4.

4 Pascoe JM, Berger A. Attitudes of high school girls in Israel and the United States toward breast feeding. I Adolesc Health Care 1985;6:28-30.

5 Jones DA. The choice to breast feed or bottle feed and influences upon that choice: a survey of 1525 mothers. Child Care Health Dev 1987;13:75-85.

(Accepted 18 April 1989)

\title{
Risks of AIDS among workers in the "sex industry": some initial results from a Scottish study
}

\author{
Ruth Morgan Thomas, Martin A Plant, Moira L Plant, David I Sales
}

Alcohol Research Group, Department of Psychiatry, University of Edinburgh, Morningside Park, Edinburgh EH10 5HF Ruth Morgan Thomas, BA, research associate Martin A Plant, PHD, director Moira L Plant, PHD, research fellow

AFRC Institute of Animal Physiology and Genetics Research, Edinburgh David I Sales, MSC, principal scientific officer

Correspondence to: $\mathrm{Ms}$ Morgan Thomas.

BrMed f 1989;299:148-9
Abstract

Objective-To determine the extent to which workers in the "sex industry" in Edinburgh engage in activities with a high risk of infection with HIV.

Design-Cross sectional, single phase survey in which respondents were located by a non-random method ("snowballing").

Setting-Research project coordinated by the Alcohol Research Group, Edinburgh.

Subjects - 205 Sex workers (102 male, 103 female) interviewed between July and December 1988.

End point-Strategies to reduce risk of AIDS among people who buy and sell sexual services.

Measurements and main results-Data were elicited by a standardised interview which related to over 300 variables. A fifth of the study group had used drugs intravenously, and one in 12 reported that they had been found to be seropositive on HIV testing. Roughly a quarter of the study group sometimes engaged in unprotected sex with clients for more money, and a similar proportion sometimes did not seek medical advice even if they had genital or anal symptoms.

Conclusions-People who buy and sell sexual services should be priority targets for health education and strategies to reduce their risk of AIDS.

\section{Introduction}

The connection between commercial sex and sexually transmitted diseases has been extensively studied. ${ }^{\prime}$ During recent years concern about this link has been heightened by the AIDS epidemic. The connection between the "sex industry" and AIDS has been further accentuated by the fact that some of those who buy and sell sexual services are heavy users of alcohol or illicit drugs. ${ }^{2+4}$

In order to examine the behavioural aspects of risks of AIDS in relation to the sex industry a research project was initiated in Edinburgh. Edinburgh city has a population of around 500000 and a high rate of HIV infection. ${ }^{56}$ At the end of March 1989, 969 people had been recorded as HIV positive by Edinburgh hospitals. Over half of these $(533 ; 55 \%)$ were intravenous drug users, some of whom were known to provide commercial sex at least occasionally (personal communications 1988(V Morrison), 1988 (J R Robertson), 1989 (D Goldberg)). Several people have reportedly been infected as a result of sexual contact with Scottish drug users.'

This investigation was designed to achieve three main aims: (a) to examine the extent to which sex workers engage in activities with a high risk of HIV infection; $(b)$ to examine levels of alcohol and drug use among sex workers; and $(c)$ to determine patterns of AIDS related beliefs, knowledge, and attitudes among sex workers. This paper is concerned with the first aim.

\section{Subjects and methods}

For this study a "sex worker" is defined as someone who provides sexual services for money. Data were elicited by a standardised interview schedule containing questions on 333 variables. It was not possible to conduct a random survey, and respondents were therefore contacted by "snowballing." interviewers approaching subjects whom they knew to be sex workers and who in turn introduced them to others. This paper relates to the first 205 sex workers who were interviewed between July and December 1988.

\section{Results}

Of the 205 sex workers, 102 were male and 103 female. Their age range was 15 to 44 . Because of nonresponse to some items in the interview the totals presented below vary slightly. Initial fieldwork concentrated on people who mainly worked the streets and from hotels, discos, and bars. This is reflected by their usual methods of meeting clients, listed in table I.

Use of condoms - The sexes did not differ significantly in relation to their self reported use of condoms with clients (table II). Most respondents reported that they always or usually used condoms for penetrative sex with clients. Even so, a minority reported that they rarely or never used condoms. Respondents were asked whether they refused to use condoms for 